\title{
Prevalence of Multidrug Resistance among Salmonella enterica Serovar Typhimurium Isolated from Pig Faeces in Ashanti Region, Ghana
}

\author{
John Osei Sekyere ${ }^{1,2}$ and Francis Adu ${ }^{1}$ \\ ${ }^{1}$ Department of Pharmacy, Faculty of Pharmacy and Pharmaceutical Sciences, Private Mail Bag Kumasi, Kumasi, Ghana \\ ${ }^{2}$ Department of Pharmacy, University of KwaZulu-Natal, Durban 4000, South Africa \\ Correspondence should be addressed to John Osei Sekyere; jod14139@gmail.com
}

Received 11 December 2014; Revised 15 January 2015; Accepted 16 January 2015

Academic Editor: Marilyn C. Roberts

Copyright (C) 2015 J. Osei Sekyere and F. Adu. This is an open access article distributed under the Creative Commons Attribution License, which permits unrestricted use, distribution, and reproduction in any medium, provided the original work is properly cited.

\begin{abstract}
Introduction. Salmonella typhimurium is associated with outbreaks of food-borne nontyphoidal salmonellosis (NTS) worldwide with marked multidrug resistance. Objectives. This study aimed to determine the prevalence of antibiotic resistant Salmonella typhimurium in pigs in Ashanti Region, Ghana. Methods. Faeces from 10 pigs per pig farm were collected and mixed to obtain 108 multiply-composite faecal samples. Standard microbiology and biochemical procedures were used to isolate and identify an S. typhimurium isolate from the composite faecal sample of each farm. Antibiotic sensitivity test was carried out to determine the sensitivity of the isolates. Discussion. From the 108 multiply-composite faecal samples, $72 \mathrm{~S}$. typhimurium isolates were obtained from 72 separate composite samples representing 72 different pig farms. Of the 72 faecal isolates, 32 (52.8\%) were resistant to at least one antibiotic. Twenty-seven isolates (71.1\%) were resistant to amoxicillin and streptomycin. Resistance to tetracycline, doxycycline, and ciprofloxacin was found in 17 (44.7\%), $15(39.5 \%)$, and 8 (21.1\%) isolates, respectively. Resistance to norfloxacin, sulphamethoxazole-trimethoprim, and gentamicin were expressed in $3(7.9 \%), 3(7.9 \%)$, and $0(0.0 \%)$ isolates, respectively. Conclusion. Multiple drug resistance is common in S. typhimurium isolates, many of which could belong to the same clone, from pigs in Ashanti Region, Ghana.
\end{abstract}

\section{Introduction}

Invasive nontyphoidal salmonellosis (NTS) caused by multidrug resistant (MDR) S. typhimurium, especially DT104, ST19, and the highly invasive ST313, is a major cause of fatal bacteraemia and infant mortality in sub-Saharan Africa. In sub-Saharan Africa, NTS are often copresented with malaria, HIV, malnutrition, and severe anaemia in infants with attributable mortality of up to $25 \%$ [1-3]. Food security and public health are affected worldwide by the recurrent but unwelcome presence of Salmonella typhimurium in food animals, besides their untold economic toll on many livestock-producing economies [4]. Very little is known of their sources, modes of transmission, and environmental reservoirs though human to human transmission in community and health care centres is observed within
Africa. Notwithstanding, studies describing the potentials of wild and domestic animals as reservoirs and sources of $S$. typhimurium in Africa are limited and this knowledge gap affects the effective implementation of prevention strategies $[3,5]$.

This study is the first to report on resistance levels and profiles of S. typhimurium isolates from pig faeces in Ashanti Region, Ghana.

\section{Methods}

2.1. Study Area, Sampling, and Demography. The study was conducted in five districts in the Ashanti Region, Ghana. These districts were suggested by the Ashanti regional Veterinary Department due to their higher density of pig farms and well established pig farmers' associations. The farms were 
situated in five districts within the Ashanti Region of Ghana: Ejisu-Juaben District (12 settlements), Atwima Nwabiagya District (12 settlements), Bosomtwe and Atwima Kwanwoma Districts (5 towns), and Kwabre East District (10 towns). Ashanti Region was chosen due to proximity to the university and the relatively larger and commercialised number of pig farms.

The farms visited were those enlisted by the pig farmers' associations in the various districts. Farms were carefully chosen from villages and towns within the districts to ensure a fair representation. Farms in which the owners were absent or unwilling to undertake the study were not included. Farms that were within proximity of 100 meters were not selected.

A total of 108 farms were obtained from the various settlements within the five districts: Ejisu Juaben (43 farms), Atwima Nwabiagya (20 farms), Bosomtwe-AtwimaKwanwoma (24 farms), and Kwabre East (21 farms).

2.2. Faecal Collection, Isolation, and Identification of S. typhimurium Isolates. Briefly, between May and July 2012, fresh faeces were collected from ten pigs in each of the 108 pig farms. These faeces were mixed up and placed into a sample tube, making 108 multiply composite faecal samples. Samples were transported to the laboratory in sample tubes on ice. Ten grams of each sample was suspended in $100 \mathrm{~mL}$ of $0.9 \%$ saline with $20 \%$ glycerol, diluted to $10^{-1}$, and immediately stored at $-20^{\circ} \mathrm{C}$ till analysis.

Stored samples were thawed, diluted to $10^{-2}$, and precultured in enriched soy peptone broth (Oxoid, Basingstoke, UK). Selenite broth (Thermo Fischer, UK), modified brilliant green agar (Thermo Fischer, UK), and the Kaufman-White typing method (scheme) were used to, respectively, select, detect, and isolate and confirm the presence of S. typhimurium as already described $[2,6,7]$. An S. typhimurium control (ATCC 14028) was used for the Kaufmann-White typing method (scheme). One isolate was used per each farm sample to represent the whole farm.

A simple questionnaire asking farmers for the antibiotics used within the last six months was also administered to guide the choice of antibiotics for sensitivity testing.

2.3. Antibiotic Sensitivity Testing. Antibiotic sensitivity testing discs (amoxicillin-10 $\mu \mathrm{g}$, ciprofloxacin-5 $\mu \mathrm{g}$, doxycycline$30 \mu \mathrm{g}$, gentamicin-10 $\mu \mathrm{g}$, norfloxacin-10 $\mu \mathrm{g}$, streptomycin$10 \mu \mathrm{g}$, sulphamethoxazole/trimethoprim-23.75/1.25 $\mu \mathrm{g}$, and tetracycline-30 $\mu \mathrm{g}$ ) from Oxoid (Oxoid, Basingstoke, UK) and a semiautomated multidisc dispenser (Oxoid, Basingstoke, UK) were used to determine the sensitivities of the isolates according to CLSI described standards and guidelines [8]. Controls were set up for every batch of plates tested using Pseudomonas aeruginosa ATCC 27853 and Escherichia coli ATCC 25922. All tests were carried out in triplicates.

The zones of inhibition produced by the antibiotics were measured thrice and the average was compared with the CLSI breakpoints [9] to determine the susceptibility of the isolates. Isolates showing susceptibility and intermediate resistance were left out in the analysis. Isolates with resistance to more than two antibiotics not belonging to the same class were classified as multidrug resistant.
TABLE 1: Summary of S. typhimurium resistance to tested antibiotics.

\begin{tabular}{lcc}
\hline Antibiotics & $\begin{array}{c}\text { Number of } \\
\text { resistant isolates } \\
(n=38)\end{array}$ & $\begin{array}{c}\text { Percentage } \\
(\%)\end{array}$ \\
\hline Amoxicillin & 27 & 71.1 \\
Ciprofloxacin & 8 & 21.1 \\
Norfloxacin & 3 & 7.9 \\
Gentamicin & 0 & 0 \\
Streptomycin & 27 & 71.1 \\
Tetracycline & 17 & 44.7 \\
Doxycycline & 15 & 39.5 \\
Sulphamethoxazole-trimethoprim & 3 & 7.9 \\
\hline
\end{tabular}

2.4. Data Analysis. The number and percentages of resistant isolates were analysed with Microsoft Excel@ 2010 (Microsoft Corporation, Microsoft Office package, 2010, USA).

2.5. Ethical Approval and Informed Consent. Ethical exemption and study approval were obtained from the Faculty of Pharmacy of the Kwame Nkrumah University of Science and Technology. The approval of the regional and district veterinary offices and the farmers were obtained before faecal collection began and, where possible, verbal consent was obtained using accepted methods [10, 11].

\section{Results and Discussion}

Each of the 108 multiply composite faecal samples comprised faeces from 10 animals per farm. From the 108 farms studied, 72 samples were positive for S. typhimurium, representing $66.7 \%$ of the farms tested. Thirty-eight isolates (52.8\%) were resistant to one or more antibiotic(s). Of these, $27(71.1 \%)$ were resistant to both amoxicillin and streptomycin. Resistance ranged from $44.7 \%$ to $39.4 \%$ for tetracycline and doxycycline, respectively, with resistance to ciprofloxacin being $21.1 \%$. Resistance to norfloxacin and sulphamethoxazoletrimethoprim (SXT) was also 7.9\%. None of the isolates were resistant to gentamicin (Table 1). Table 2 shows the spectrum of antibiotics to which the isolates were multiply resistant. The total number of multidrug resistant isolates reduced with increasing number of antibiotics with 29 (76.3\%) of the resistant isolates and $40.3 \%$ of all 72 isolates being multidrug resistant. Eighty-five percent (85.2\%) of amoxicillin-resistant isolates were also resistant to streptomycin.

The study resulted in an isolation rate of $72 \mathrm{~S}$. typhimurium isolates out of the 108 composite faecal samples (66.7\%), which is higher than the $50 \%$ obtained by Oliveira et al. from pig faeces in Brazil [12] and the $13.1 \%$ salmonellae isolated from 153 cloacal swabs from free range chickens in Abeokuta, Nigeria, by Ojo and peers [13]. Thirty-eight out of 72 isolates (53\%) from 72 multiply composite faecal samples were resistant to at least one antibiotic tested. The higher levels of resistance identified in the isolates to amoxicillin, streptomycin, and the tetracyclines commensurate with the types of antibiotics used by the farmers and also observed by Osei Sekyere $[14,15]$ by pig farms in Ashanti Region. This 
TABLE 2: Antibiotic spectrum of multidrug resistant S. typhimurium porcine faecal isolates.

\begin{tabular}{lcc}
\hline Antibiotics & $\begin{array}{c}\text { Number of } \\
\text { multidrug } \\
\text { resistant isolates } \\
(n=29)\end{array}$ & $\begin{array}{c}\text { Percentage of } \\
\text { multidrug } \\
\text { resistant isolates } \\
(\%)\end{array}$ \\
\hline $\begin{array}{l}\text { Amoxicillin and streptomycin } \\
\text { Amoxicillin, streptomycin, } \\
\text { and ciprofloxacin }\end{array}$ & 23 & 79.3 \\
$\begin{array}{l}\text { Amoxicillin, streptomycin, } \\
\text { ciprofloxacin, tetracycline, } \\
\text { and doxycycline }\end{array}$ & 6 & 24.1 \\
$\begin{array}{l}\text { Amoxicillin, streptomycin, } \\
\text { tetracycline, and doxycycline }\end{array}$ & 12 & 20.7 \\
$\begin{array}{l}\text { Amoxicillin, streptomycin, } \\
\text { tetracycline, doxycycline, and } \\
\text { sulphamethoxazole- } \\
\text { trimethoprim }\end{array}$ & 2 & 41.4 \\
$\begin{array}{l}\text { Amoxicillin, streptomycin, } \\
\text { ciprofloxacin, tetracycline, } \\
\text { doxycycline, and } \\
\text { sulphamethoxazole- } \\
\text { trimethoprim } \\
\begin{array}{l}\text { Ciprofloxacin, tetracycline, } \\
\text { and doxycycline }\end{array}\end{array}$ & 6.9 \\
\hline
\end{tabular}

parallelism in antibiotic usage and resistance suggests a link between antibiotics used and bacterial resistance. The higher percentage of isolates with concomitant multidrug resistance to amoxicillin, streptomycin, and the tetracyclines (Table 2) also adds up to the evidence.

In a study by Ojo and colleagues [13] among 153 free range chickens in Nigeria, 20 salmonellae species isolated from 153 cloacal swabs were resistant to enrofloxacin [90.9\%], streptomycin [81.8\%], ampicillin [80\%], norfloxacin [63.6\%], tetracycline [35\%], and ciprofloxacin [0\%], respectively. With the exception of the fluoroquinolones, the findings in Nigeria are similar to that of this study. The differences in animals studied (chickens against pigs) and their management systems (free range against intensive) could account for the differences in resistance to streptomycin, ampicillin, and tetracycline. Moreover, this study only focused on S. typhimurium and not all salmonellae as was the case with the Nigerian study.

Further studies would be needed to determine the resistance mechanisms in the resistant isolates and determine the type of $S$. typhimurium clones that are circulating within the pig farms.

\section{Conclusion}

There is a substantial presence of multidrug resistant $S$. typhimurium isolates in pigs in the Ashanti Region.

\section{Conflict of Interests}

The authors declare that they have no competing interests and the sponsors had no role or whatsoever in the preparation of the paper, data collection, and analysis and decision to publish.

\section{Acknowledgments}

This research was partially funded by the ADMER project (STATENS SERUM INSTITUT, Denmark). The author thanks the farmers and the executives of the pig farmers' associations in all the districts visited for their cooperation and participation, the veterinarians of the districts visited, and the regional veterinarian for their inputs towards this research, Professor D. B. Okai for his assistance with questionnaires and information on pig science, Dr. Benard Keraita, Mr. Francis Adu, and Mrs. Vivian Etsiapa Boamah for their technical and literary assistance. The authors also thank the anonymous reviewers for their helpful comments.

\section{References}

[1] M. A. Gordon, "Invasive non-typhoidal Salmonella disease: epidemiology, pathogenesis and diagnosis," Current Opinions in Infectious Diseases, vol. 24, no. 5, pp. 484-489, 2011.

[2] F. Bager and J. Petersen, "Sensitivity and specificity of different methods for the isolation of Salmonella from pigs," Acta Veterinaria Scandinavica, vol. 32, no. 4, pp. 473-481, 1991.

[3] S. C. Morpeth, H. O. Ramadhani, and J. A. Crump, "Invasive non-typhi Salmonella disease in Africa," Clinical Infectious Diseases, vol. 49, no. 4, pp. 606-611, 2009.

[4] S. B. Baloda, L. Christensen, and S. Trajcevska, "Persistence of a Salmonella enterica serovar Typhimurium DT12 clone in a piggery and in agricultural soil amended with Salmonellacontaminated slurry," Applied and Environmental Microbiology, vol. 67, no. 6, pp. 2859-2862, 2001.

[5] B. N. Parsons, S. Humphrey, A. M. Salisbury et al., "Invasive non-typhoidal Salmonella typhimurium ST313 are not hostrestricted and have an invasive phenotype in experimentally infected chickens," PLoS Neglected Tropical Diseases, vol. 7, no. 10, Article ID e2487, 2013.

[6] M. Y. Popoff and L. L. Minor, Antigenic Formulae of the Salmonella serovars, WHO Collaboration Centre for Reference and Research on Salmonella, Institut Pasteur, Paris, France, 1997.

[7] P. R. Davies, F. G. E. M. Bovee, J. A. Funk, F. T. Jones, W. E. M. Morrow, and J. Deen, "Isolation of Salmonella serotypes from feces of pigs raised in a multiple-site production system," Journal of the American Veterinary Medical Association, vol. 212, no. 12, pp. 1925-1929, 1998.

[8] Clinical and Laboratory Standards Institute (CLSI), Methods for Dilution Antimicrobial Susceptibility Tests for Bacteria That Grow Aerobically, CLSI document M07-A9, Clinical and Laboratory Standards Institute, Wayne, Pa, USA, 9th edition, 2012.

[9] Clinical and Laboratory Standards Institute (CLSI), "Performance standards for antimicrobial susceptibility testing; twentysecond informational supplement," CLSI Document M100-S22, Clinical and Laboratory Standards Institute, Wayne, Pa, USA, 2012.

[10] I. Bourgeault, R. Dingwall, and R. de Vries, Sage Handbook on Qualitative Health Research, Sage, London, UK, 2010.

[11] D. Padgett, Qualitative and Mixed Methods in Public Health, Sage, Thousand Oaks, Calif, USA, 2010.

[12] C. J. B. Oliveira, L. F. O. S. Carvalho, and P. E. N. Givisiez, "Detection of Salmonella enterica in porcine faecal samples by different isolating and enrichment broth cultivation-PCR methods," Revista Portuguese De GienciasVeterinarias, vol. 100, no. 555-556, pp. 193-198, 2005. 
[13] O. E. Ojo, O. G. Ogunyinka, M. Agbaje, J. O. Okuboye, O. O. Kehinde, and M. A. Oyekunle, "Antibiogram of Enterobacteriaceae isolated from free-range chickens in Abeokuta, Nigeria," Veterinarski Arhiv, vol. 82, no. 6, pp. 577-589, 2012.

[14] J. Osei Sekyere, "Types and selling practices of antibiotics in veterinary shops in Ashanti Region, Ghana," Journal of Food, Agriculture and Veterinary Science, vol. 4, no. 2, pp. 87-96, 2014.

[15] J. Osei Sekyere, "Antibiotic types and handling practices in disease management among pig farms in Ashanti Region, Ghana," Journal of Veterinary Medicine, vol. 2014, Article ID 531952, 8 pages, 2014. 

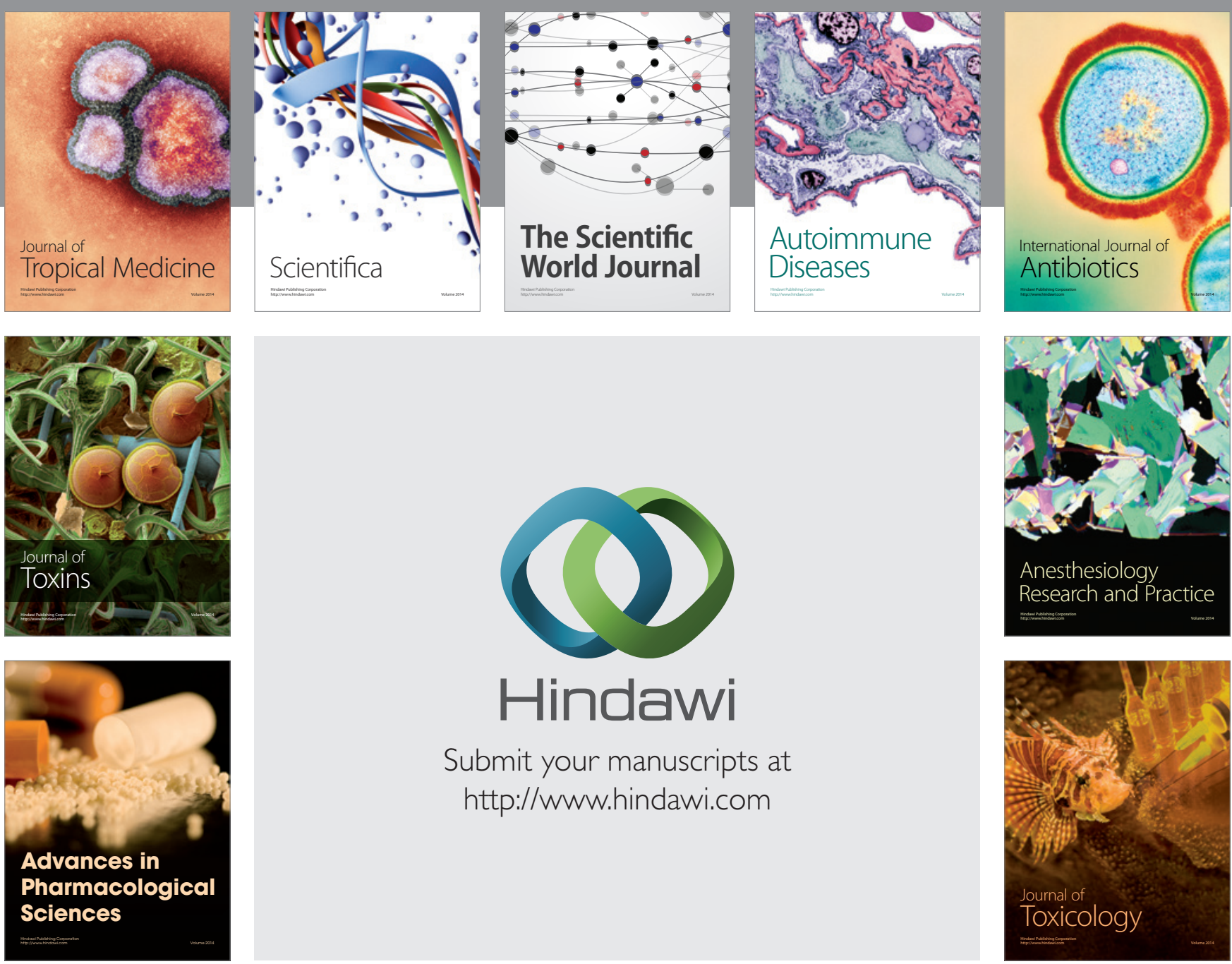

\section{Hindawi}

Submit your manuscripts at

http://www.hindawi.com
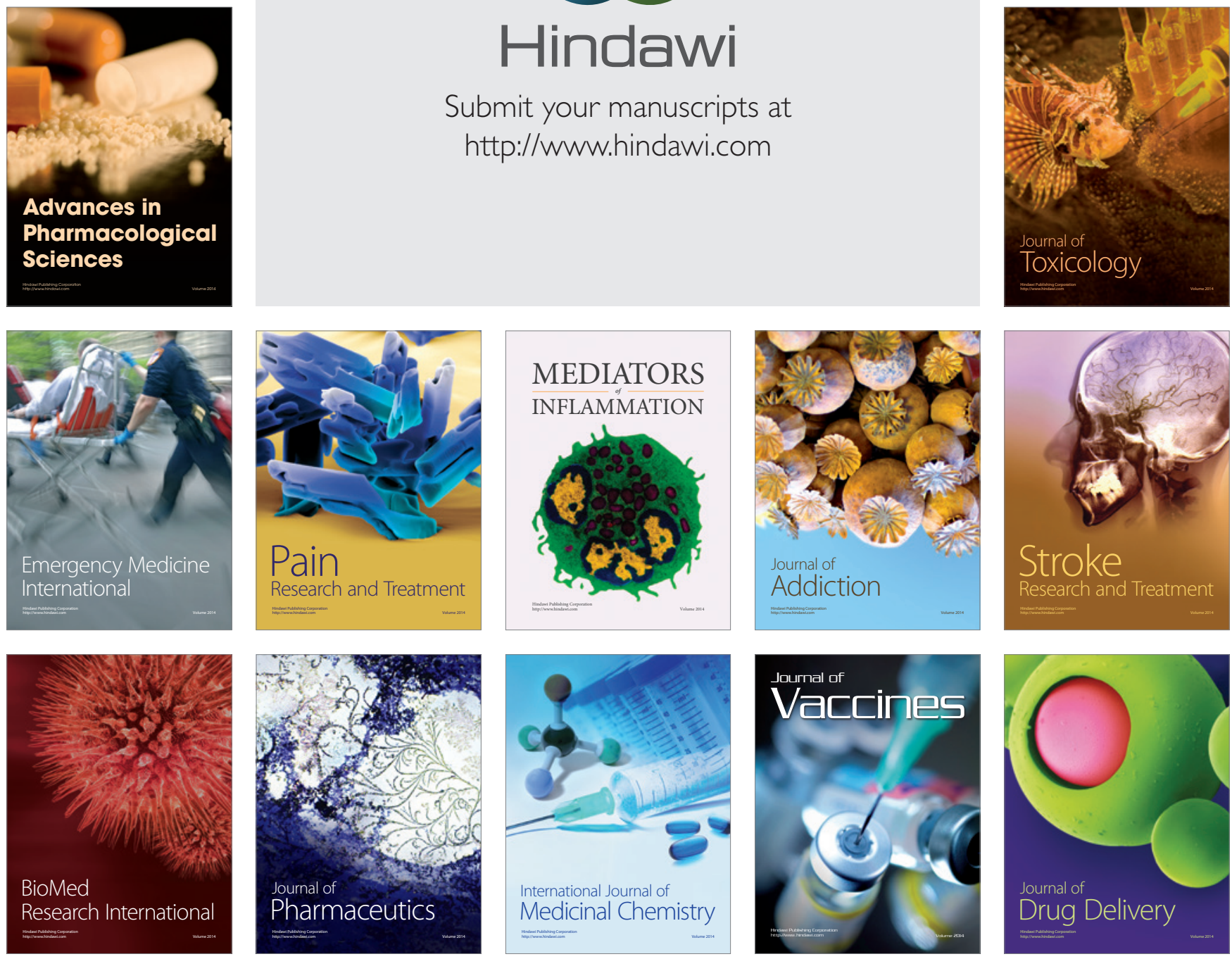